\title{
An operational model for the implementation of computerised school information systems
}

\author{
C.J.P. Nolan, D.A. Ayres and D.H. McKinnon \\ Massey University, Palmerston North, New Zealand \\ Phone: (64)-6-3504577 Fax: (64)-6-3505619 \\ e-mail: P.Nolan@massey.ac.nz
}

\begin{abstract}
The paper presents an operational model for the implementation of computerised school information systems and it conceptualises implementation as complex, interrelated with other processes and problematic. In order to explain implementation, viewed in this way, the model links Levels of Use from the Concerns Based Adoption Model (CBAM) devised by Hall, Wallace \& Dossett (1973) with generic change processes shown by research to be constitutive of educational change and innovation in educational institutions. Discussion suggests ways by which practitioners and researchers, alike, might employ the Model to better manage the implementation of computerised systems and better understand the factors and forces affecting implementation.
\end{abstract}

\section{Keywords}

Educational management, administration, implementation, information technology

\section{INTRODUCTION}

In this paper, we develop an operational model for the implementation of computerised school information systems. The model provides strategies for both managing and researching the complexity, inter-relatedness, and problematic nature of implementation. It uses concepts from both educational change theory (Fullan, 1991; Fullan, 1993; McKinnon, Nolan, Openshaw \& Soler, 1991; Ruddick, 1991; Adams \& Chen, 1981; Hall, Wallace, \& Dosset, 1973) and computer assisted school administration (CASA) research (e.g. Visscher, 1996; Visscher, 1991; Visscher and Spuck, 1991).

Change theory contributes an understanding of the innovative (and thereby potentially problematic) character of computerised information systems (Nolan, Ayres, Dunn and McKinnon, 1996). When first introduced to schools, computerised systems typically challenge individuals to modify, perhaps even abandon, tried and seemingly-true ways of doing things and replace them with alternative and new methods, behaviours and ways of thinking. 
Furthermore, change theory (Fullan, 1991) by identifying implementation as one of three stages in the change process, along with adoption and utilisation, is consistent with the theoretical model (Visscher, 1991) most commonly used to conduct CASA research. The Model was designed to analyse the development, use and impact of computerised administration systems. In a recently updated version (hereafter called the Visscher Model), Visscher (1996) identifies features of the implementation process as a key variable which directly affects the magnitude and manner in which information systems are utilised and, in turn, the extent of their impact.

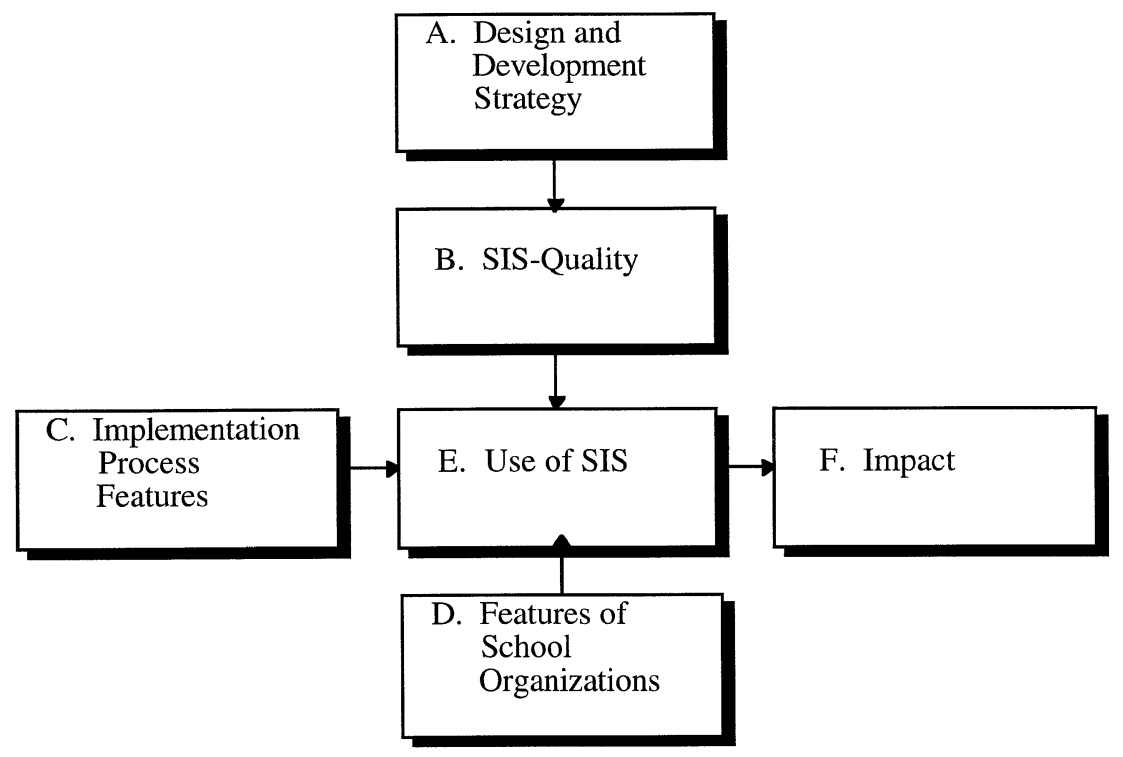

Figure 1 Visscher's (1996) Model of the Development, Use and Impact of Computerised School Information Systems (SISs).

In the Model, Blocks A, C, and E identify the computer system-related processes which impact on computer assisted school administration (CASA), namely, system development, implementation and use.

Within CASA, implementation of changes (e.g., acquisition of a new application or replacement of the existing computer platform) is strategic in the sense that it lies at the interface between the intentions of developers and the ways that information systems are actually used. If this is the case, then effective implementation strategies appear to be a key factor influencing the extent to which such systems may enhance school administration and management and impact positively upon the content and delivery of school education.

To date, the Visscher Model has been successfully used as a framework within which to examine "top-down" approaches to computerised school information system development and adoption (Visscher and Spuck, 1991). Our purpose, here, is to extend its application to capture the dynamics of development and adoption when a "bottom-up" approach is employed. Such an approach predominates in New Zealand.

New Zealand schools (Nolan and Ayres, 1996), must elect to use computerised information systems because the Government has maintained a policy of noninvolvement. The predominant system, MUSAC (Massey University School Administration by Computer), has been designed and developed by a self-funded 
University research and development centre, using a "bottom-up" approach which consisted of: (i) initial system development for a small group of schools; (ii) further development of the system for all schools; and (iii) the ongoing development of the system based on feedback from users (see Nolan and Ayres, 1996). This stands in contrast with a "top-down" approach which typifies computerised information system development, implementation and use in countries where schools are mandated by government to adopt computer assisted school administration.

It is in the nature of "top-down" approaches to simplify the three change processes of system development, implementation and use into a linear sequence to be worked through in a step-wise progression. In reality, the processes are inherently complex and inter-related (Nolan, Ayres, Dunn \& McKinnon, 1996). A "bottom-up" approach explicitly acknowledges the complexity and inter-relatedness by identifying interactions between the processes of development, implementation and use as essential. For example, with the MUSAC system in New Zealand (see Nolan and Ayres, 1996), the relationship between development and use is reflected in the constant flow of information and ideas between users and developers. This, in turn, results in the developers constantly changing the configuration and capabilities of the system in response to user suggestions.

New Zealand research (Nolan et al, 1996) has shown that schools were able to deal with both the complexity and the inter-related aspects of change when they employed an adaptive yet systematic methodology. Use of the methodology, in its turn, provided empirical support for the model of implementation and its conceptualisation that is the main topic of this paper.

\section{THE IMPLEMENTATION MODEL}

The Implementation Model presented here takes Levels of Use from the Concerns Based Adoption Model (CBAM) (Hall, Wallace \& Dossett, 1973) and links them with the three generic processes of innovation adoption, implementation and utilisation now commonly identified in the literature (Fullan, 1991; McKinnon, Nolan, Openshaw \& Soler, 1991; Ruddick, 1991; Adams \& Chen, 1981) as constitutive of change in educational institutions.

CBAM was developed and applied in the 1970s and 1980s (Hall et al, 1973; McKinnon \& Nolan, 1989) specifically to assist researchers and practitioners to analyse and manage educational change through innovation. The model specifies a hierarchy of eight "Levels of Use" (see Figure 2). The levels depict behaviours which individuals exhibit over time in relation to the innovation and they provide an indication of the progress of the innovation, itself.

Figure 2 shows how the eight Levels of Use correspond with the three change processes, (i.e., adoption, implementation and utilisation), and indicates a degree of overlap. The overlap occurs because orientation can occur in both the adoption and implementation stages of the change process, and mechanical use can occur in both the implementation and utilisation stages. Furthermore, while it is possible to make analytical distinctions between adoption, implementation and utilisation, they stand in a relationship of interdependency. That is to say, the practicality of change taking place at several levels simultaneously, e.g., institutional, group and individual, means that the boundaries between the three processes are, in reality, blurred. 


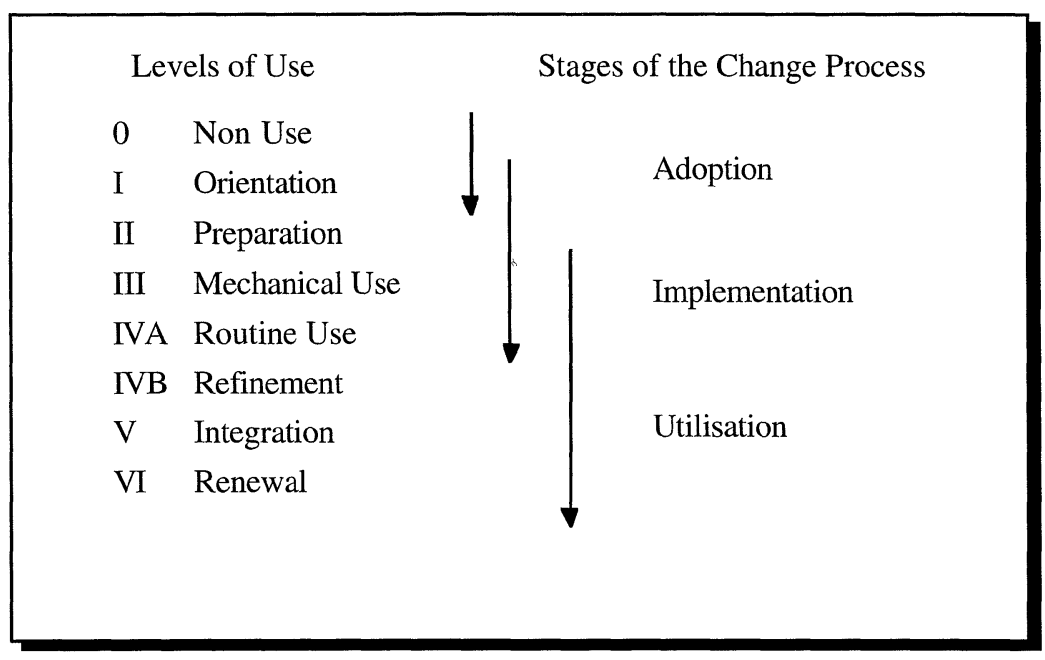

Figure 2 Implementation Model for Computerised School Information Systems.

\subsection{Adoption}

Typically, innovation adoption includes development of awareness that a situation needs to be addressed, and orientation activities which predispose decision-makers to take a particular course of action (Hall et al., 1973). Together, awareness and orientation lay the foundation for implementation.

Developing awareness involves key personnel recognising that a computerised information system may actually be needed. The reasons may range from systemic pressures from a higher authority (e.g. the Ministry of Education in New Zealand) through community pressures to internal school reasons.

In the adoption stage, orientation involves key personnel seeking knowledge and ideas which will inform their decisions. For instance, it is likely that they will wish to know about such matters as tasks the computerised system will perform, the kinds of outcomes that might be expected, the levels of funding and support that might be required to both acquire and implement the system, and the relative merits and shortcomings of competing systems.

\subsection{Implementation}

It is often the case that the decision to adopt a computerised information system is made by administrators or other people in authority. This may not always be the case, though, as some schools may use inclusive decision-making strategies. Depending upon the strategies that a school actually uses to reach the decision to adopt, varying numbers of personnel will have been through orientation when implementation begins.

Furthermore, the manner in which adoption is carried out may either support or impede implementation and thus affect the eventual utilisation of the new system. This is suggested by the inclusion of Features of Schools as Organisations in Block D of the Visscher Model. 
The specification of implementation in Figure 2 as covering orientation, preparation and mechanical Levels of Use, captures the essentially introductory character of implementation activity. While key decision-makers in the adoption stage may have successfully oriented themselves towards the innovation, those personnel who are starting at the level of non-use will require orientation in order to accept the innovation and perceive it as valuable to them and their institution (McKinnon et al, 1991). It is in this respect, that implementation of a computerised school information system (innovation) may be problematic.

The preparation Level of Use engages personnel in the activities of setting up the system for practical use. Typically, this level of use includes acquisition and installation of the system, the determination of locations (e.g. where to place the file server and remote networked terminals), the assignment of staff roles and responsibilities, and the initiation of staff training.

Mechanical use, the final implementation step, involves staff members learning to use the system. Implementation ends when everyone who the school identifies as needing to use the system (or a part of it), has mastered the program(s) and is using it to carry out day-to-day tasks.

\subsection{Utilisation}

In the Visscher Model, utilisation is represented in Block E, Use of SIS. Figure 2 shows that utilisation is characterised by the remaining four Levels of Use in CBAM. These are: routine use where "attention shifts from the management of computerisation to the management of information" (Visscher, 1991:3), and the execution, by computer, of day to day administrative and clerical activities; refinement where the school may modify the system, or parts of it, to suit their own specific needs and requirements; integration where school staff understand ways by which computerised administration can, and does, support not just specific and school-wide management decisions but also learning and teaching; and renewal where the users evaluate the quality of use of the innovation and examine new developments with a view to setting new goals.

Once integrated into a school's day-to-day administrative and operating procedures, the quality of use is evaluated in terms of impact outcomes as signified by Block F, Impact, in the Visscher Model. To the extent that the evaluations are favourable, a school may decide to expand the existing system by introducing a new component, i.e., initiate a new implementation stage. In this way, implementation can be seen to be typically on-going and incremental as schools progressively adopt new components of a system.

\section{DISCUSSION}

At the point of writing, only limited case study research (Nolan, Ayres, Dunn \& McKinnon, 1996) has been conducted using the Implementation Model presented here. The research indicated, however, that the Model and the operational definitions derived from it, provided a framework within which: (i) researchers can study and document the form and direction that schools might take to implement computerised information systems; and (ii) the schools, themselves, might implement a computerised system, and evaluate their implementation endeavours.

A seemingly successful implementation strategy commonly employed involves the following four steps:

1. document the existing situation through an administrative review and/or needs analysis to identify actual needs and possible directions;

2 . do collaborative problem solving to analyse the results and determine goals, priorities and the resources and support required, based on the results; 
3. key staff who will drive the innovation, formulate a detailed implementation plan including staff training and support to develop the necessary confidence and competencies; and

4. carry out regular, well-structured staff training and support on an as-needs basis, thereby enabling staff to learn and master specific programs by using them to complete real management and administration tasks.

While all the steps were necessary, the fourth is vital. Schools known to have implemented computerised systems effectively (i.e. they had progressed to a stage of routine and integrated use) commonly employ the services of an external support agency to help them take the fourth step and frequently the others as well. Somewhat ironically, many agencies, in their turn, have come to understand that their aims and objectives must include: (i) helping schools to increasingly take responsibility for meeting their own learning needs; and (ii) empowering schools to implement and use their computerised administration systems relatively unaided.

The steps, above, correspond with the awareness, orientation, preparation and mechanical use activities identified in the Implementation Model. Its initial use in chronicalling the way schools progress through the steps of implementation suggest both a strategy that schools might adopt and a set of propositions that researchers might test in future research on the implementation of computerised school information systems.

The new conceptualisation stands somewhat in contrast with the way that implementation is viewed in the Visscher Model which conceptualises school information systems as complex products of a finite design and development process. Consequently, implementation is also conceptualised as a process with a definite beginning and end, contained within one block of the Model.

While the conceptualisation of implementation presented here fits within the Visscher (1996) framework, the research conducted to date, and experience, show that the complexity of change means that implementation activities are on-going and incremental and they interact with factors in all the other blocks of the Model rather than being contained just within one block, i.e., Block C, Implementation Process Features.

Thus, implementation must be viewed as on-going, incremental, and interactive, rather than as a finite process. For instance, specific features of the school as an organisation (Block D) interact with implementation in ways that can either impede or support it. For example, in a recent secondary school case study (Nolan et al, 1996) a team approach, involving collaboration between teachers and administrative staff across organisational levels and departmental boundaries, demonstrated how a positive school climate can support implementation. In this case, staff took ownership of, and became committed to, the process. Collaboration and team work fostered staff perceptions that their work, using the system, was of real value to the school. This, in its turn, elevated the status of staff by recognising them as individuals with skills and expertise important to the team and the school.

At another level, the interaction of implementation with design and development strategies (Block A) can lead to better and simpler ways to manage school information. In New Zealand, where a "bottom-up" approach to system development and design predominates, developers constantly refine the system used by most schools by inviting users to suggest improvements. This results in system quality (Block B) constantly being enhanced by the injection of ideas from actual users. Through this interaction, implementation is also enhanced by the sense of involvement that users have in the design of the system (Block A in the Visscher Model). In this way, the system has been made more "user-friendly" since its initial inception and it produces output which the end-users perceive as valuable (Block F, Impact).

If the existing Visscher Model were further developed to include the conceptualisation of implementation presented here then its scope might be expanded to include a wider range of school information systems and educational systems. If this were to happen, its explanatory power and capability to enhance practice would also be enhanced. In this way, two seemingly desirable consequences may more easily eventuate. Firstly, 
practitioners (support agencies, teachers and school administrators) might be better placed to more effectively adopt and implement computerised information systems and use them more effectively to achieve desirable administration, management and educational outcomes. Secondly, researchers might be better placed to unravel the complexity and problematic aspects which have made adoption, implementation and utilisation of computerised systems such a difficult exercise in the past and continue to do so.

\section{REFERENCES}

Adams, R.S. \& Chen, D. (1981) The process of educational innovation: an international perspective. Kogan Page, London.

Fullan, M. (1991) The new meaning of educational change. Columbia University, Teachers College Press, NY.

Fullan, M. (1993) Change forces: probing the depth of educational reform. Falmer Press, London.

Hall, G.E., Wallace, R.C. \& Dosset, W.A. (1973) A developmental conceptualisation of the adoption process with educational institutions. The University of Texas, Austin.

McKinnon, D.H. \& Nolan, C.J.P. (1989) Using computers in education: a concernsbased approach to professional development for teachers. The Australian Journal of Educational Technology, 5(2), 113-131.

McKinnon, D.H., Nolan, C.J.P., Openshaw, R. and Soler, J. (1991) New Zealand curriculum innovation in historical and political context: the Freyberg integrated studies project and parallel projects of the 1940s. Journal of Curriculum Studies, 23(2), 155-175.

Nolan, C.J.P. \& Ayres, D.A. (1996) Developing a "good" information for schools: the New Zealand experience. Forthcoming in International Journal of Educational Research, 25(4).

Nolan, C.J.P., Ayres, D.A. Dunn, S. \& McKinnon, D.H. (1996) Implementing computerised school information systems: case studies from New Zealand. Forthcoming in International Journal of Educational Research, 25(4).

Ruddick, J. (1991) Innovation and change. Milton Keynes: Open University Press.

Visscher, A.J. (1991) School administrative computing: a framework for analysis. Journal of Research on Computing in Education, 24(1), 1-19.

Visscher, A.J. (1996) Information technology in educational management as an emerging discipline. Forthcoming in International Journal of Educational Research, 25(4).

Visscher, A.J. and Spuck, D.W. (1991) Computer assisted school administration and management: the state of the art in seven nations. Journal of Research on Computing in Education, 24(1), 146-168.

\section{BIOGRAPHIES}

Pat Nolan is a Professor in the Massey University Department of Educational Psychology and Director of the Massey University Educational Research and Development Centre. His professional and research interests include curriculum development and design, education with computers, experiential education, educational administration and management and school development.

Debbie Ayres is lecturer in the Massey University Department of Educational Psychology. Her professional and research interests include curriculum development 
and design, educational administration and management with computers and early childhood education.

David McKinnon is a senior lecturer in teacher education at Charles Sturt University, Mitchell, Australia. His professional and research interests include professional development for teachers, education with computers and science education. 